Article

\title{
Long-Term Behavior of Fuel Vapor Retaining Systems for Pure (E0) and Blended Fuels (E10) Part 2: Regeneration with Nitrogen of $70 \%$ Relative Humidity
}

\author{
Manfred Ulrich Göbel ${ }^{1}$, Jürgen U. Keller ${ }^{1}$, Karl Meller ${ }^{2}$, Ingo Schmitz ${ }^{1}$, Thomas Seeger ${ }^{1,3}$ (1) \\ and Eva Schieferstein ${ }^{2, *} * \mathbb{B}$ \\ 1 Department of Maschinenbau, the Institute of Fluid and Thermodynamics, University of Siegen, \\ D-57076 Siegen, Germany; ulrich.goebel@uni-siegen.de (M.U.G.); juergen.keller@uni-siegen.de (J.U.K.); \\ ingo.schmitz@uni-siegen.de (I.S.); thomas.seeger@uni-siegen.de (T.S.) \\ 2 Department of Products, Fraunhofer Institute UMSICHT, D-46047 Oberhausen, Germany; \\ karl.meller@umsicht.fraunhofer.de \\ 3 Center for Sensor Systems (ZESS), D-57076 Siegen, Germany \\ * Correspondence: eva.schieferstein@umsicht.fraunhofer.de
}

check for

updates

Citation: Göbel, M.U.; Keller, J.U.;

Meller, K.; Schmitz, I.; Seeger, T.;

Schieferstein, E. Long-Term Behavior of Fuel Vapor Retaining Systems for Pure (E0) and Blended Fuels (E10) Part 2: Regeneration with Nitrogen of $70 \%$ Relative Humidity. Processes 2022, 10, 397. https://doi.org/ $10.3390 /$ pr10020397

Academic Editors: Pawel Sobieszuk, Jacek Gebicki and Piotr Rybarczyk

Received: 20 January 2022

Accepted: 14 February 2022

Published: 18 February 2022

Publisher's Note: MDPI stays neutral with regard to jurisdictional claims in published maps and institutional affiliations.

Copyright: (C) 2022 by the authors. Licensee MDPI, Basel, Switzerland. This article is an open access article distributed under the terms and conditions of the Creative Commons Attribution (CC BY) license (https:// creativecommons.org/licenses/by/ $4.0 /)$.

\begin{abstract}
In gasoline-driven vehicles, fuel vapor retaining systems are used to prevent the emission of hydrocarbons from the fuel tank into the atmosphere. In this paper, which is Part 2 of our publication, measurements of regeneration processes of the activated carbon by flushing it with humid nitrogen gas of $70 \%$ relative humidity are represented. Using purge air with high relative humidities, representing realistic conditions, it can be observed that water is accumulated in the activated carbon. For ethanol-containing fuel blends, additional accumulation of ethanol in the carbon occurs, decreasing the adsorption capacity of the carbon for standard fuel's components considerably. State-of-the-art testing procedures use purge air with about $50 \%$ relative humidity for the regeneration of the activated carbon filters. As this often does not represent real operation conditions, the working limits of the fuel vapor retaining systems could not be identified up to now. Furthermore, the determination of the butane working capacity as a quality parameter of the fuel vapor retaining systems is also based on the assumption of relatively low air humidity. Consequently, a new quality criterion has to be established.
\end{abstract}

Keywords: activated carbon filter; adsorption behavior; fuel vapor mix; fuel vapor retaining system; Raman spectroscopy

\section{Introduction}

Since the 1970s, fuel vapor retaining systems (FVRS) have been used in gasolinepowered vehicles to prevent emissions of fuel vapors into the environment. According to the Renewable Energy Directive RED I (2009/28/EC) [1] and the Renewable Energy Directive RED II (Directive (EU) 2018/2001) [2], up to at least 14\% of renewable energy should be used in the transport sector. The addition of bioethanol seems to play an important role in this. However, detailed effects of the use of bioethanol fuel blends on the functionality of the FVRS are currently unknown.

Results of a Technical Inspection Association (TÜV) study [3] show that the FVRS fail more frequently in long-term use with the gasoline-ethanol blend E5 (5 vol \% ethanol in gasoline). The reason for this is assumed to be that ethanol reduces the working capacity of the activated carbon [3]. This hypothesis is supported by the fact that high ethanol concentrations were detected in the activated carbon after a long period of use of the activated carbon filters [3,4]. In addition, investigations by the European Commission [5] focused on the rinsing process of the activated carbon, with particular attention being paid to the rinsing time. Among other things, it was found [5] that ethanol has a higher affinity 
for activated carbon than hydrocarbons, which can lead to a reduction in the adsorption capacity of the activated carbon for hydrocarbons.

The verification of the functional capability of the activated carbon filters is described in the Type-IV test [6]. This test describes in detail the conditions of the canister fuel aging, but in all regulations [6,7], there is no information about what humidity the purge air should contain. Therefore, a relative humidity (RH) of $50 \pm 10 \%$ is often assumed. The effect of higher moisture content of the purge air on the long-term behavior of the activated carbon filters is not considered.

In actual operation, the FVRS is purged by drawing in ambient air. If the relative humidity of the ambient air in Germany [8] is considered, it is always above $70 \% \mathrm{RH}$. Since the activated carbon filter is a lifetime component, it is important to ensure its long-term stability even when using bioethanol blends during regeneration with a realistic humid ambient air.

In the first part of the article [9], the measurement results for the tests with E0 (100\% npentane as gasoline substitute fuel) or E10 (10 vol \% ethanol in $90 \mathrm{vol} \% \mathrm{n}$-pentane) and dry purge $\mathrm{N}_{2}$ were addressed. Here, the results obtained when purging with moist $\mathrm{N}_{2}$ $(70 \% \mathrm{RH})$ are presented and discussed.

\section{Materials and Methods}

In principle, in the following figures, all individual data points are connected by interpolated lines as a visual aid.

\subsection{Determination of the Evaporative Emissions (Type-IV Test)}

To prevent emissions of volatile components of fossil fuels into the environment, activated carbon filters are used, which completely adsorb the vapors emitted from the tank under all operating conditions. The necessary regeneration of the activated carbon filter takes place cyclically by flushing with ambient air and releasing the volatile organic compounds desorbed into the engine intake tract. The aging process of activated carbon filters is described in ANNEX I of "Regulation No 692/2008" "Determination of evaporative emissions (Type-IV test)" [10]. The quantity used to check the functionality of the activated carbon filter is the butane working capacity (BWC). Its determination is regulated in American Society for Testing and Materials (ASTM) standard D 5228 [11]. It is a measure of the ability of activated carbon to adsorb and desorb butane from dry air under defined conditions. According to the Type-IV test, the BWC is determined over 150 cycles and should not fall below 95\% of the original BWC.2.2. Activated Carbon and Adsorptives.

The most commonly used activated carbon in the FVR systems is BAX 1100. The pore structure of the activated carbon was investigated by $\mathrm{N}_{2}$ adsorption at $-196{ }^{\circ} \mathrm{C}$. The isotherm obtained is shown in Figure 1. BAX 1100 is characterized by a high specific surface area of approximately $1300 \mathrm{~m}^{2} / \mathrm{g}$ and a high proportion of micropores and mesopores (Figure 1). It has a bulk density of $355 \pm 30 \mathrm{~g} / \mathrm{L}$.

The adsorption isotherms for n-pentane and ethanol on the BAX 1100 can be found in [9].

For the investigations discussed here, water adsorption is of central importance. Figure 2 illustrates the water adsorption isotherm of BAX 1100 at $24^{\circ} \mathrm{C}$. It was determined by using two different methods, thus demonstrating the reproducibility of the results. The course of the adsorption isotherm-type $\mathrm{V}$ according to International Union of Pure and Applied Chemistry (IUPAC) - is typical for the sorption of water vapor on activated carbons. Due to the strong hydrophobicity of BAX 1100, it hardly adsorbs any water up to relative humidities of $50-60 \%$. Adsorption by capillary condensation only increases sharply above approx. $70 \% \mathrm{RH}$. During desorption, a strongly pronounced hysteresis is observed with a remaining residual load. 


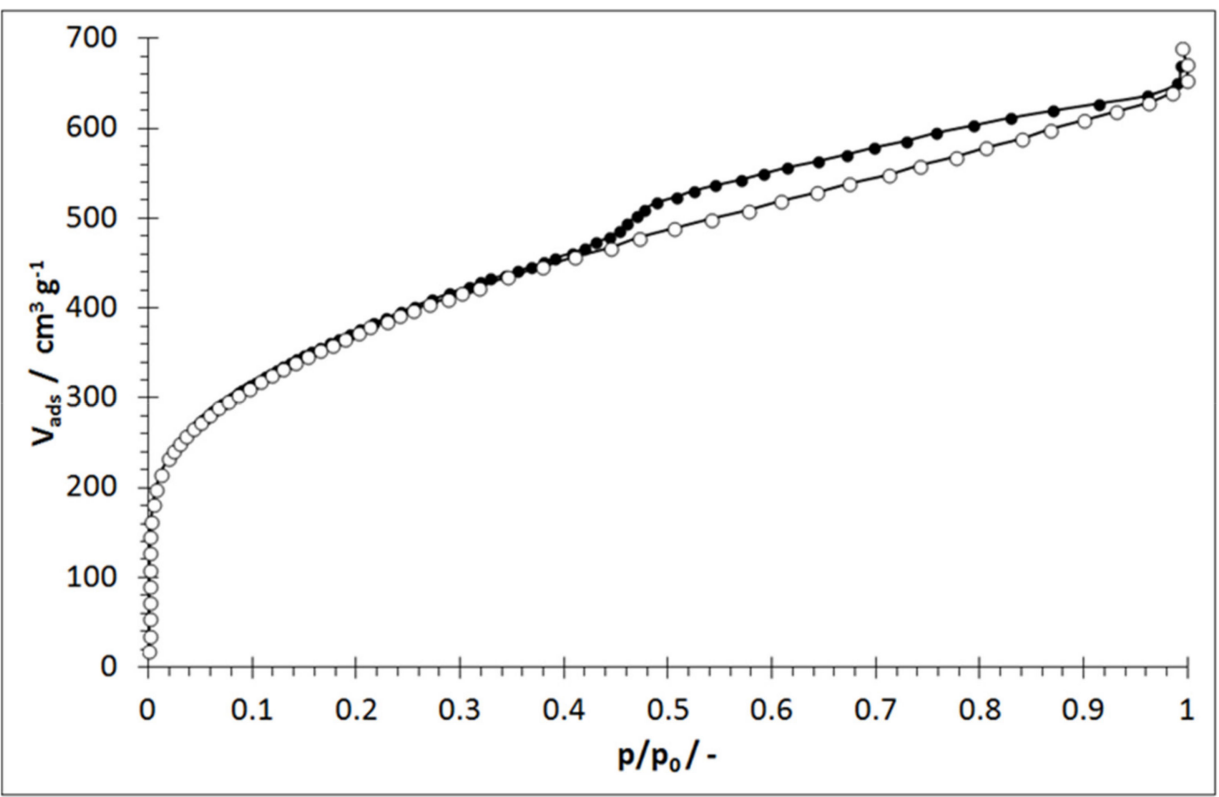

Figure 1. Nitrogen adsorption isotherm of BAX 1100 at $\mathrm{T}=-196{ }^{\circ} \mathrm{C}, \mathrm{p}_{0}\left(-196^{\circ} \mathrm{C}\right)=1013.5 \mathrm{hPa}$.

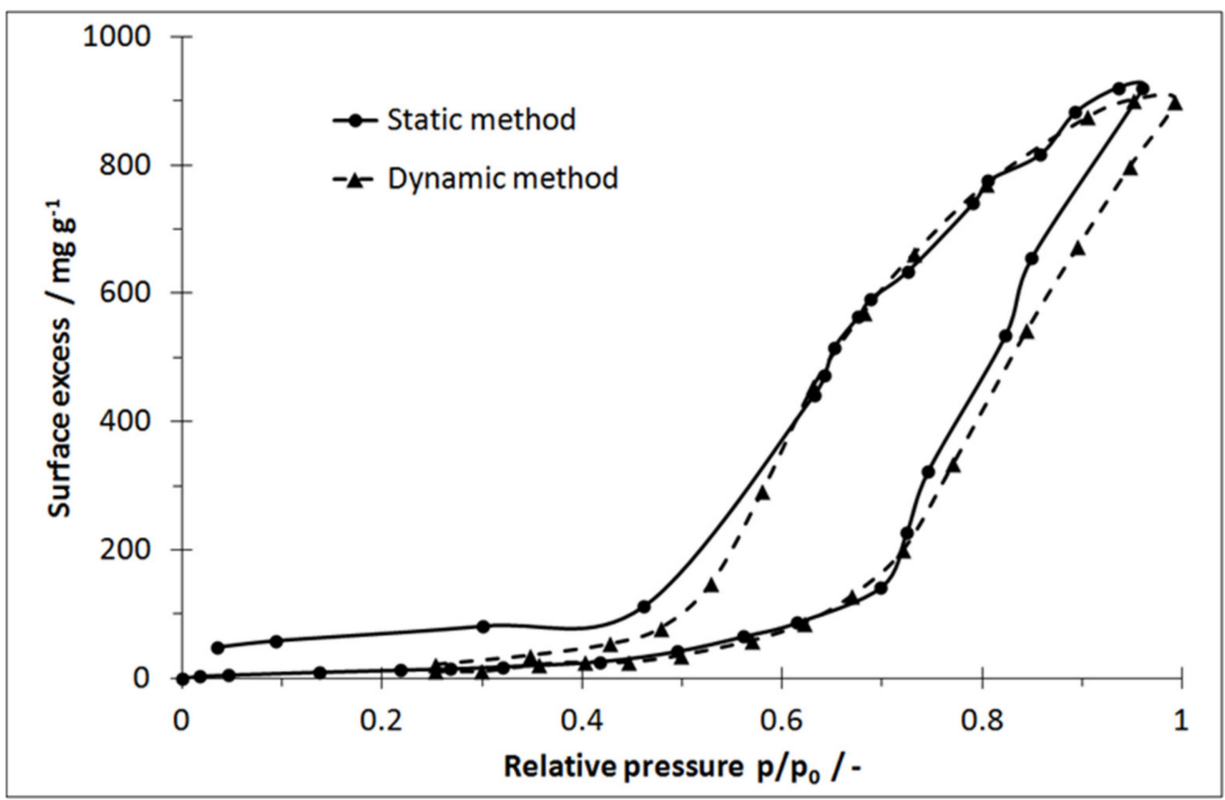

Figure 2. Adsorption of water vapor on BAX 1100 at $\mathrm{T}=24^{\circ} \mathrm{C}, \mathrm{p}_{0}\left(24^{\circ} \mathrm{C}\right)=29.8 \mathrm{hPa}$.

The investigations were carried out with the adsorptive n-pentane (E0) as a representative substitute fuel for certified gasoline [12] and bio-ethanol in the mixture with n-pentane as a biofuel blend (E10).

Based on the course of the water isotherm, which only shows a considerable uptake of water at higher water concentrations, and due to the fact that the relative humidity of the air in Germany is always above $70 \%$ relative humidity throughout the year [8], the experiments were carried out with nitrogen at a relative humidity of $70 \%$ at $24{ }^{\circ} \mathrm{C}$.

Nitrogen $\left(\mathrm{N}_{2}\right)$ was used as the carrier gas for all components used, namely water, $\mathrm{n}$-pentane, and ethanol. In the purge phase, $\mathrm{N}_{2}$ was loaded with water vapor up to a relative humidity of $70 \%$. The $\mathrm{N}_{2}$, in each case as a substitute for air, was present in purity 5.0, the water as a monodistillate. The n-pentane of purity $>94 \mathrm{vol} \%$ (Stockmeier Chemie, Duisburg, Germany) was used. The ethanol from the agricultural origin (Fa. Südzucker AG, Mannheim, Germany) had a purity of $99.85 \mathrm{vol} \%$ and was undenaturated. 
The adsorptive concentrations for the fuel vapors were:

E0: 70 vol \% n-Pentane and 30 vol \% $\mathrm{N}_{2}$.

E10: 46 vol \% n-Pentane, 3 vol \% ethanol, and 51 vol \% $\mathrm{N}_{2}$.

From this, the thermodynamics of ideal gas mixtures was used to calculate the fuel vapor rate with $20 \mathrm{~L} / \mathrm{h} \mathrm{N}_{2}$ as a carrier gas:

$$
\mathrm{E} 0: \dot{m}_{E 0} \approx 40 \mathrm{~g} / \mathrm{h} \quad \mathrm{E} 10: \dot{m}_{E 10} \approx 27 \mathrm{~g} / \mathrm{h}
$$

Consequently, the fuel respectively adsorptive vapor rate was larger for E0 than for E10 [9].

\subsection{Determination of the Breakthrough Behavior}

To determine the breakthrough behavior of activated carbon filters, the time- and location-dependent sorption processes were investigated experimentally by simultaneously measuring the temperature behavior and the fuel vapor concentrations. For this purpose, an activated carbon tank with a volume of $1 \mathrm{~L}$ was used. The experimental procedure was slightly modified based on the results obtained with dry purge $\mathrm{N}_{2}$ [8]. As the results for E10 showed [9], ethanol broke through at a maximum concentration of 3 vol \%. Therefore, for the following studies, it was assumed that the breakthrough ethanol concentration was negligible compared to the pentane concentration. The system was reprogrammed to sum only the breakthrough-pentane signal from a Raman detector until the limit of $2 \mathrm{~g}$ was reached. The Raman detector includes a cw Nd: $\mathrm{YVO}_{4}$ laser, which operates at $\lambda=532 \mathrm{~nm}$. The Raman signals are measured by a spectrometer (Ocean Optics, Duiven, The Netherlands) in combination with a back-thinned charge couple device (CCD) chip. The laser beam is focused on a test cell. The Raman scattered light is collected perpendicular to the incident laser beam by a telescope with a large solid angle on the collecting side and an optical filter to suppress the unwanted Rayleigh signal. The light is then focused into an optical fiber with a $200 \mu \mathrm{m}$ core diameter and guided to a spectrometer with a back-thinned CCD area sensor with a peak quantum efficiency of $90 \%$. Thermal noise is minimized by thermal conditioning of the CCD detector. The detectable spectral range is from $530 \mathrm{~nm}$ to $620 \mathrm{~nm}$ resulting in a Raman shift from $0 \mathrm{~cm}^{-1}$ to $2700 \mathrm{~cm}^{-1}$. In order to increase the Raman signal intensities considerably and, as a result, to achieve short measurement times, a multipass approach was used. More details on the Raman detector can be found in [13-18]. When the above-described limit is reached, the system is switched from adsorption to a hold time of $10 \mathrm{~min}$ and then purged with nitrogen in countercurrent. The experimental procedure for the long-term experiments with moist nitrogen as purging gas was as follows (Table 1). All tests were carried out at $24{ }^{\circ} \mathrm{C}$.

Table 1. Procedure of the experiments with humid $\mathrm{N}_{2}$ as purge gas at $24{ }^{\circ} \mathrm{C}$.

(a) Measurement of the species behind the filter during the loading with E0- or E10-vapor criterion for technical breakthrough: mass of n-pentane having passed the FVRS, $2 \mathrm{~g}$

(b) Holding time [10]: $10 \mathrm{~min}$

(c) Countercurrent purge $(1 \mathrm{~h})$ : exchange of 300 bed volumes with $3001 / \mathrm{h} \mathrm{N}_{2}(70 \% \mathrm{RH})$

More detailed information on the experimental procedure can be found in [9], and the experimental setup is explained in detail in [19]. In the following text, from the total of eight thermocouples used, reference is made only to the data of four (T305, T310, T315, T320), which are marked in bold in Figure 3. 


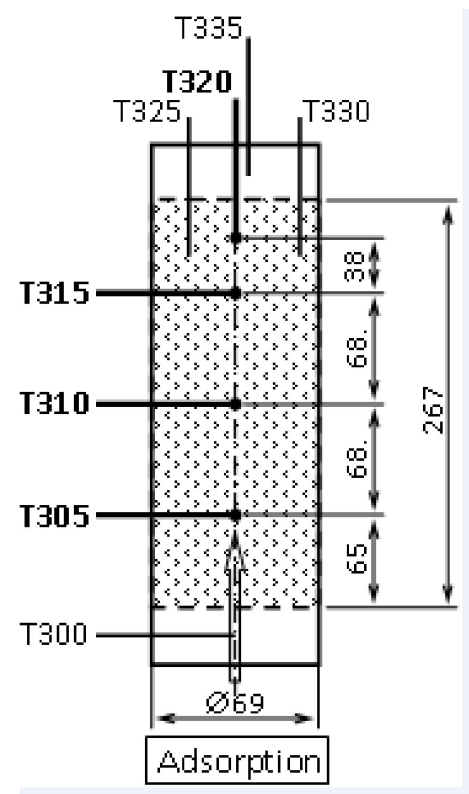

Figure 3. Schematic structure of the activated carbon filter with the thermocouples used (size indication in $\mathrm{mm}$ ).

\subsection{Determination of Water Content of the Activated Carbon Bed}

The water content of the activated carbon bed was determined by Karl Fischer titration. This was done with the Titrator of Schott "TitroLine KF" (SI Analytics, Mainz, Germany). To ensure the correctness of this method in the presence of ethanol, Imidazole and Methylimidazole were added to the Karl Fischer reagent so that the real water content was determined.

\section{Results and Discussion}

\subsection{Analysis of Long-term Experiments with EO and Humid Nitrogen ( $70 \%$ RH)}

Figure 4 shows the concentration and temperature curve for the 10th cycle of long-term measurement. It is evident that the pentane initially adsorbs completely until it begins to break through after approx. 750 measuring points. After 1020 measuring points, i.e., after approx. $51 \mathrm{~min}$, the maximum pentane concentration is detected. Reaching the maximum pentane concentration is followed by a holding time of $10 \mathrm{~min}$. Then, desorption starts for $1 \mathrm{~h}$ in countercurrent with humid nitrogen loaded with $70 \%$ relative humidity. In addition, the temperature curve in the adsorber is shown using the example of four thermocouples distributed axially in the activated carbon filter. The adsorption front moves from the bottom to the top of the adsorber, i.e., initially, an evolution of heat is observed at the bottom of the adsorber (T305). Subsequently, the adsorption front moves further upwards in the adsorber so that first the thermocouple T310, T315, and finally T320, which is located at the upper end of the activated carbon bed, detect the heat tint. In the 10th cycle, the temperature difference between T305 and T320 is approximately $15^{\circ} \mathrm{C}$.

In Figure 5, the analog measurement results for the 250th cycle are shown. The time until the pentane breaks through completely has shortened to only $44 \mathrm{~min}$. In addition, the temperature behavior in the adsorber has changed fundamentally. After 297th cycle, the highest temperature is found at the bottom of the adsorber, while it is colder at the top. Here, the temperature difference between top and bottom is approx. $13^{\circ} \mathrm{C}$.

The investigation of the $\mathrm{E} 0 / 70 \% \mathrm{RH} \mathrm{N} \mathrm{N}_{2}$ system shows that the temperature behavior in the activated carbon filter changes with increasing cycle number (Figure 6). While in the initial cycles, the temperature in the activated carbon filter increases upward (T320 > T305) as the number of cycles increases, the temperature decreases at the top until the temperature distribution is reversed so that $\mathrm{T} 320<\mathrm{T} 305$. This behavior can be explained by the 
introduction of water into the activated carbon filter by countercurrent flushing with moist $\mathrm{N}_{2}(70 \% \mathrm{RH})$. A more detailed explanation follows in Section 3.1.1.

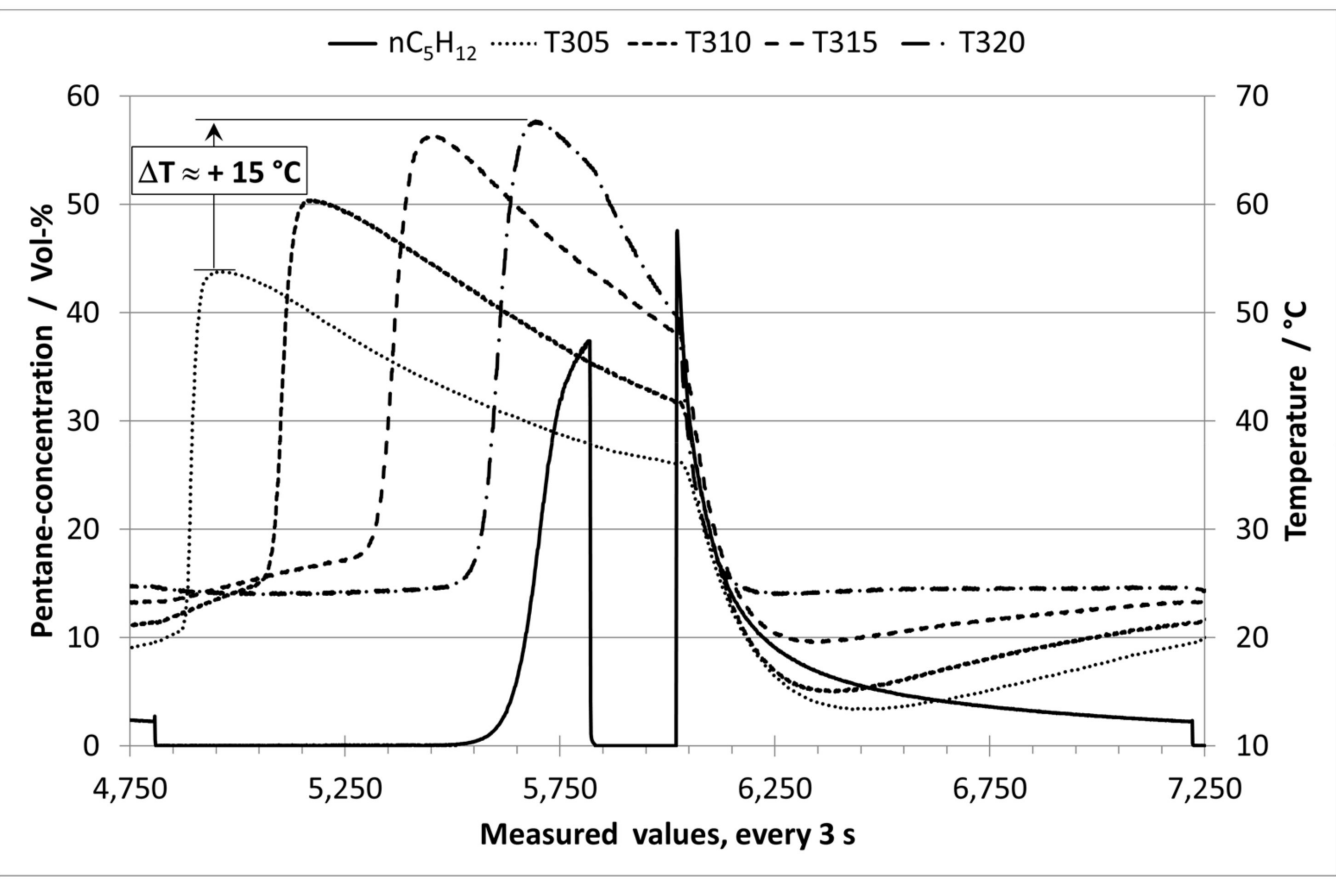

Figure 4. Concentration and temperature profile in the filter for E0/humid $\mathrm{N}_{2}$ in 10 th cycle.

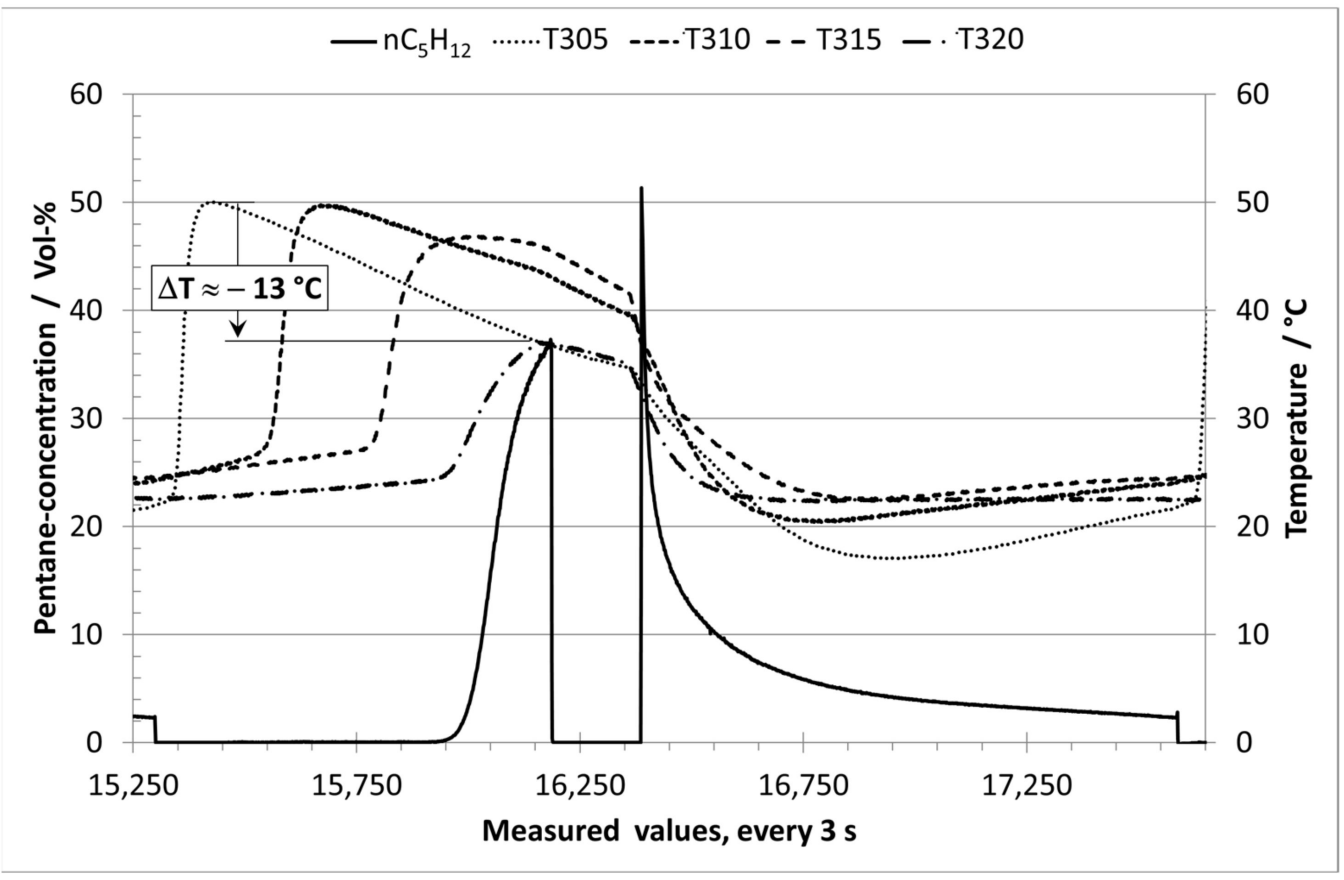

Figure 5. Concentration and temperature profile in the filter for E0/humid $\mathrm{N}_{2}$ in 250th cycle. 


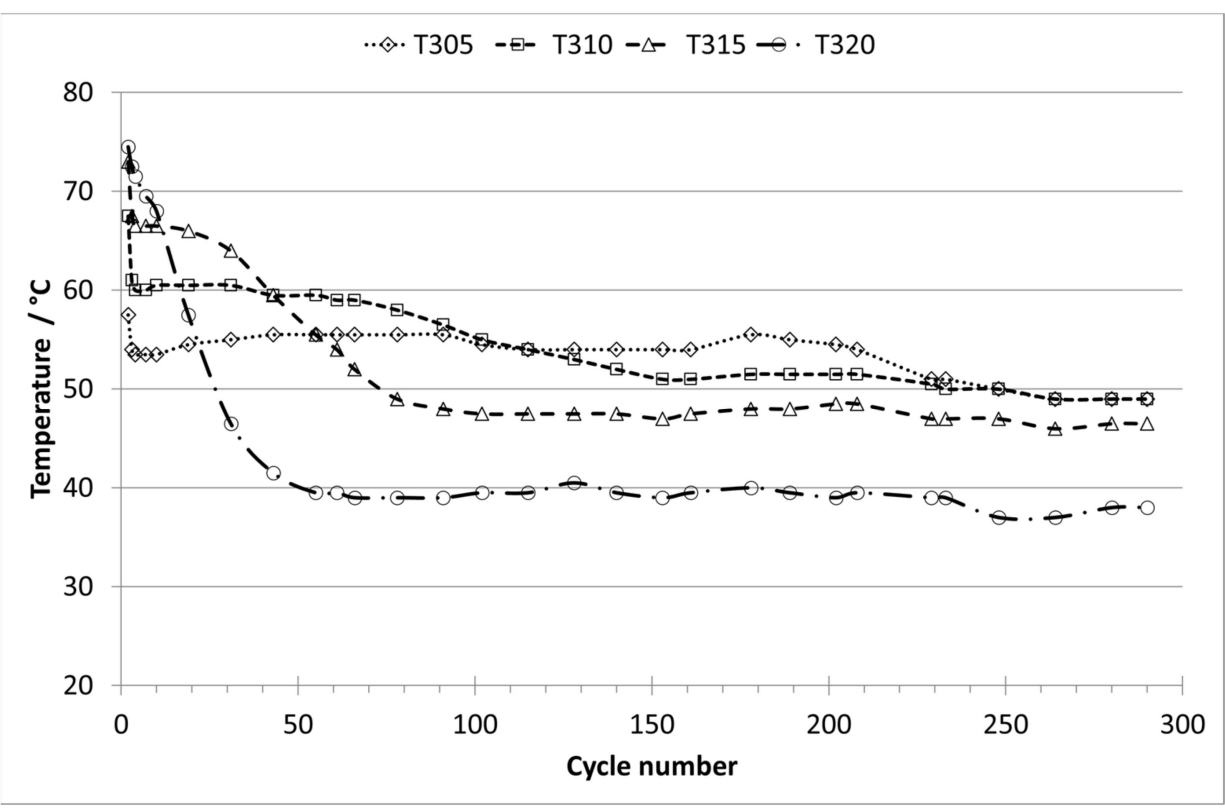

Figure 6. Dependence of the temperature behavior on the cycle number for E0/humid $\mathrm{N}_{2}$.

\subsubsection{Water Content of the Activated Carbon for the system E0/humid $\mathrm{N}_{2}$}

To determine the water content of the activated carbon bed, samples were taken at different heights of the filter and analyzed by Karl Fischer titration. For this purpose, activated carbon samples were taken from the bottom, middle, and top of the filter at the end of adsorption in the 300th cycle. The water content was highest at the top of the filter at $39.5 \mathrm{wt} \%$ and decreased towards the bottom (see Figure 7).

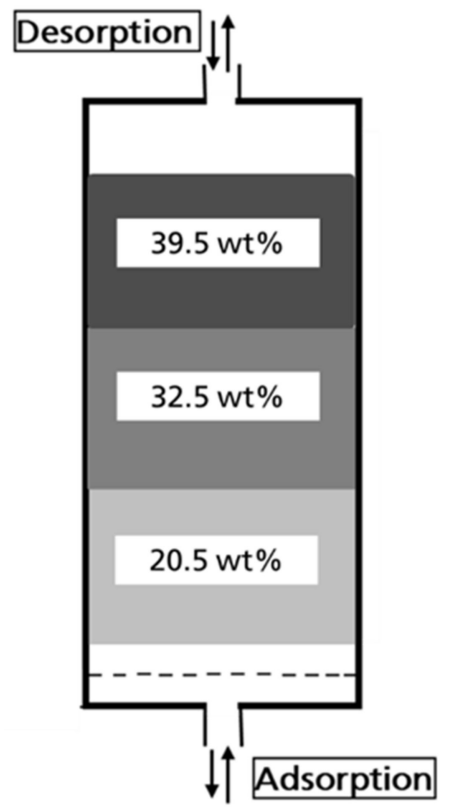

Figure 7. Water content of the activated carbon bed after adsorption in the 300th cycle.

These results show that during adsorption in the 300th cycle, a large amount of water is already present in the activated carbon filter. This water is introduced into the bed by the regeneration of the activated carbon with moist nitrogen after each adsorption cycle. Since desorption takes place in countercurrent to adsorption, i.e., from top to bottom, the water enters the activated carbon filter from above, where it then accumulates in the activated carbon bed. 
As adsorption progresses, the front of the adsorption heat moves from the bottom to the top of the activated carbon bed. This was found in the measurements with dry flushing nitrogen [9].

In the case of the regeneration of the activated carbon with humid $\mathrm{N}_{2}(70 \% \mathrm{RH})$, the conditions are changed. Due to the introduction of water from above into the activated carbon bed, on the one hand, active centers of the activated carbon are occupied by water so that the adsorptive E0 or E10 is adsorbed less. The heat of adsorption released decreases accordingly.

On the other hand, capillary condensation of the water occurs when a certain water concentration is exceeded. The water, then present in liquid form, acts as a temperature sink due to its high heat capacity, causing the temperature at the top of the activated carbon bed to drop.

\subsection{Analysis of Long-term Experiments with E10 Vapor Phase and Humid Nitrogen (70\% RH)}

Figure 8 shows the concentration and temperature curve for the 10th cycle of a longterm measurement of E10 during regeneration with moist $\mathrm{N}_{2}$. The results are similar to those in Figure 4, with pentane breakthrough occurring after approximately $49 \mathrm{~min}$. Again, there is a temperature difference between T305 and T320 of about $16{ }^{\circ} \mathrm{C}$, and the temperature in the filter increases from bottom to top.

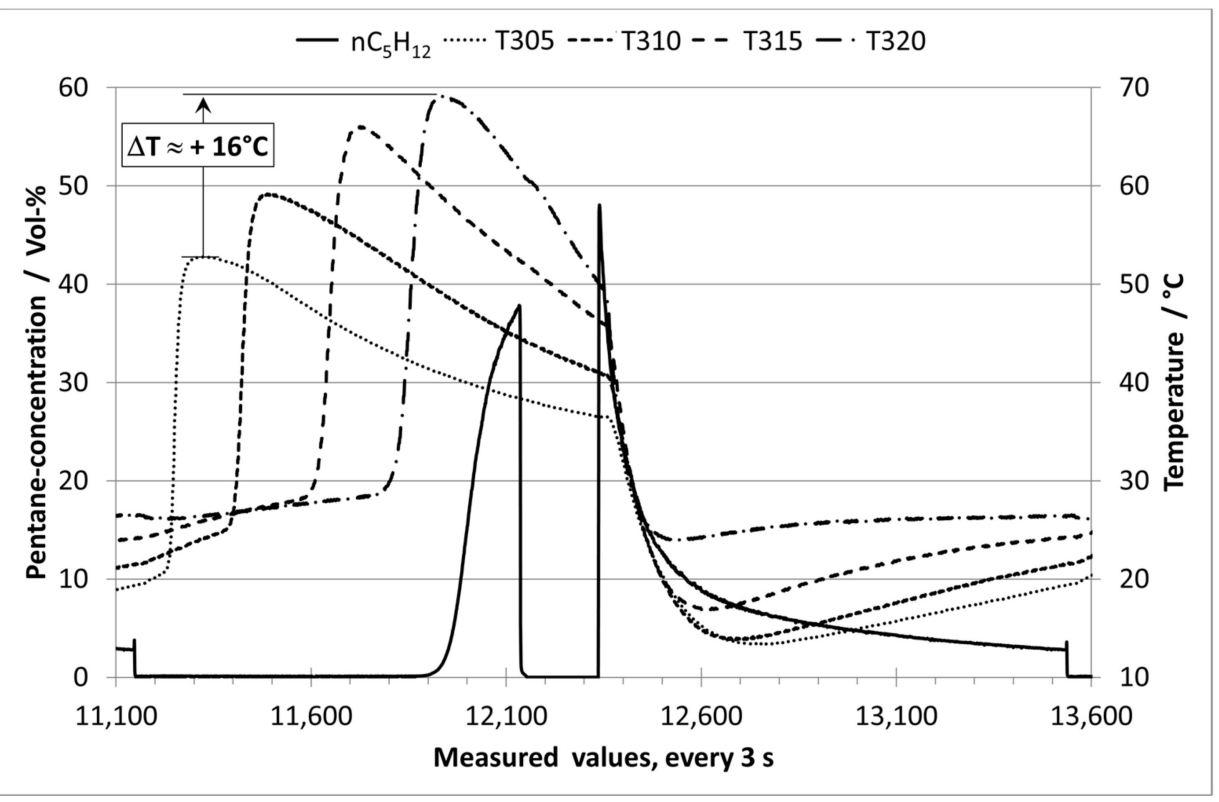

Figure 8. Concentration and temperature profile in the filter for E10/humid $\mathrm{N}_{2}$ in 10th cycle.

The following figure (Figure 9) shows the measurement results for the 250th cycle. After approx. $43 \mathrm{~min}$, the breakthrough threshold of the pentane (see Table 1) is reached. Taking into account the lower fuel rate of $27 \mathrm{~g} / \mathrm{h}$ of E10 compared to $40 \mathrm{~g} / \mathrm{h}$ of E0, the equally long breakthrough time means that the capacity of the activated carbon is considerably lower when E10 is used. While in the case of pure pentane (E0), about $28 \mathrm{~g}$ of pentane can be passed over the activated carbon before the pentane reaches its breakthrough threshold, this is only about $18 \mathrm{~g}$ in the case of E10. 


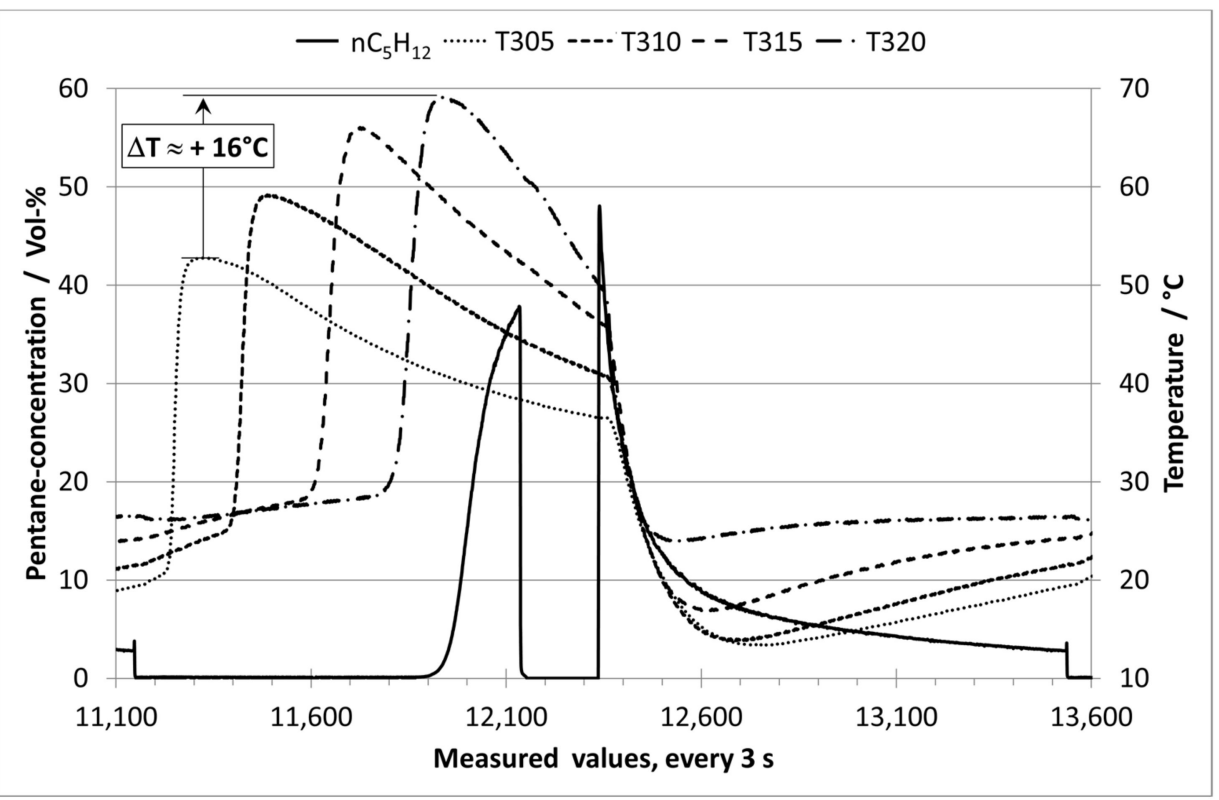

Figure 9. Concentration and temperature profile in the filter for E10/humid $\mathrm{N}_{2}$ in 250th cycle.

The temperature behavior in the filter changed considerably. The temperatures nearly equalized throughout the filter bed.

These temperature changes with the number of cycles are shown in Figure 10. This change in the temperature behavior of the activated carbon filter can be explained, as in the case of the $\mathrm{E} 0 /$ moist $\mathrm{N}_{2}$ system, by the entry of water through rinsing with $70 \% \mathrm{RH}$ nitrogen. This water accumulation is impressively confirmed by the Karl Fischer titrations.

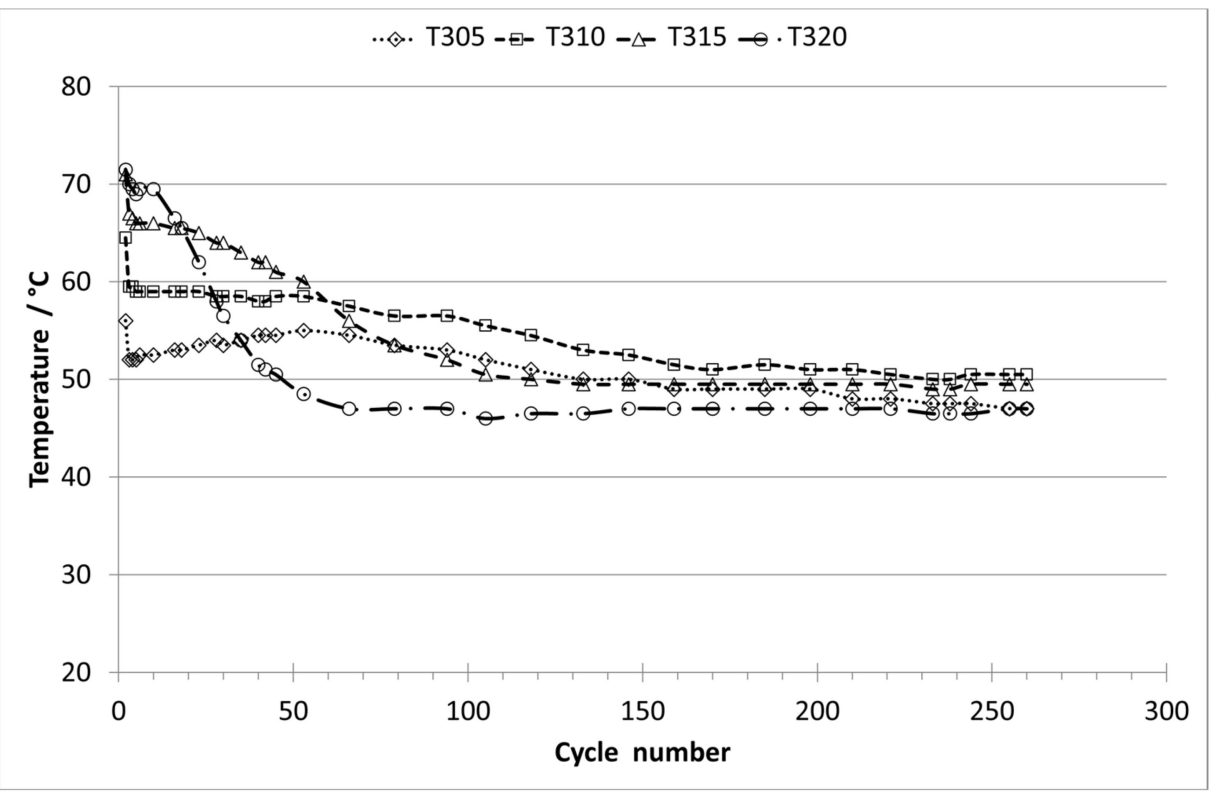

Figure 10. Dependence of the temperature behavior on the cycle number for E10/humid $\mathrm{N}_{2}$.

\subsubsection{Water Content of the Activated Carbon for the System E10/humid $\mathrm{N}_{2}$}

For this experiment, too, the water content of the activated carbon bed was determined by Karl Fischer titration. However, here the samples were taken from the filter after desorption had taken place in the 260th cycle. Again (Figure 11), the water content was highest at the top of the activated carbon filter and then decreased towards the bottom. 
The absolute values were still somewhat higher than in the experiment with E0 and moist nitrogen.

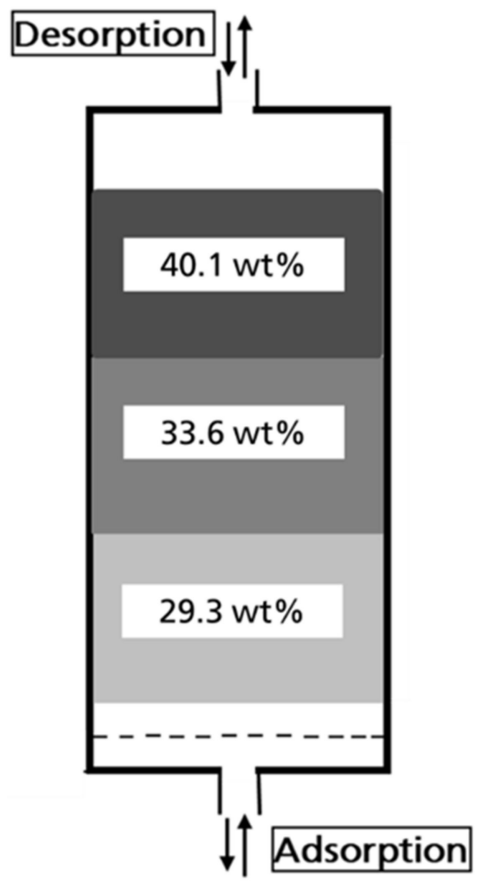

Figure 11. Water content of the activated carbon bed after desorption in the 260th cycle.

\subsection{Comparison of the Experiments with E10 and Purging with Dry or Humid Nitrogen}

When conducting an experiment with E10 and dry nitrogen to purge the activated carbon filter, it is seen that as the pentane breaks through, ethanol also breaks through according to its vapor pressure at the prevailing experimental conditions (Figure 12). This behavior occurs in all cycles and can be clearly seen in Figure 12 for cycles 8 and 77. Concentration data were taken every $3 \mathrm{~s}$.

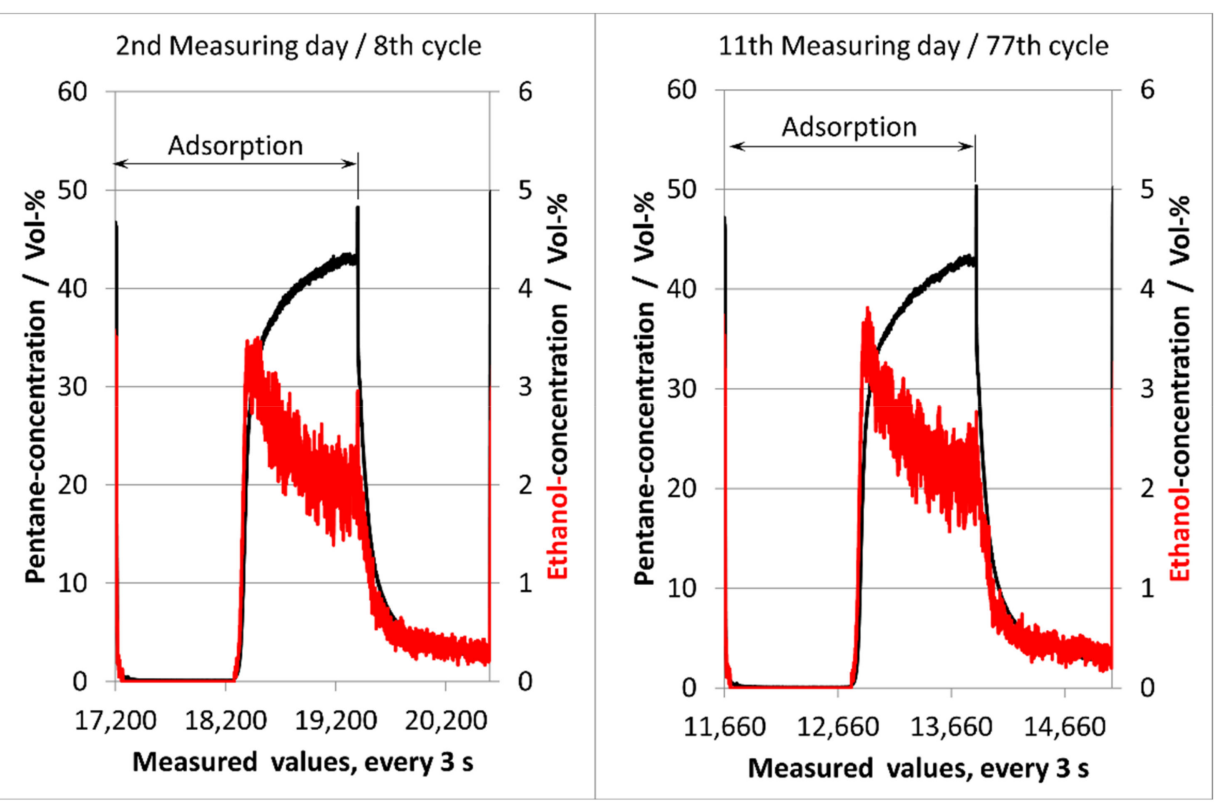

Figure 12. Breakthrough of ethanol for the system E10/dry $\mathrm{N}_{2}$ in the 8th and 77th cycles.

In the case of the system E10 and moist nitrogen $(70 \% \mathrm{RH})$ as flushing gas, the following breakthrough behavior (Figure 13) over all cycles of the experiment is seen. The 
water breakthrough with a concentration of about $2.5 \mathrm{vol} \%$, which corresponds to the partial pressure of the water at the prevailing temperature, is obvious. With the pentane, however, no ethanol breaks through here, quite in contrast to the experiment with dry flushing nitrogen.

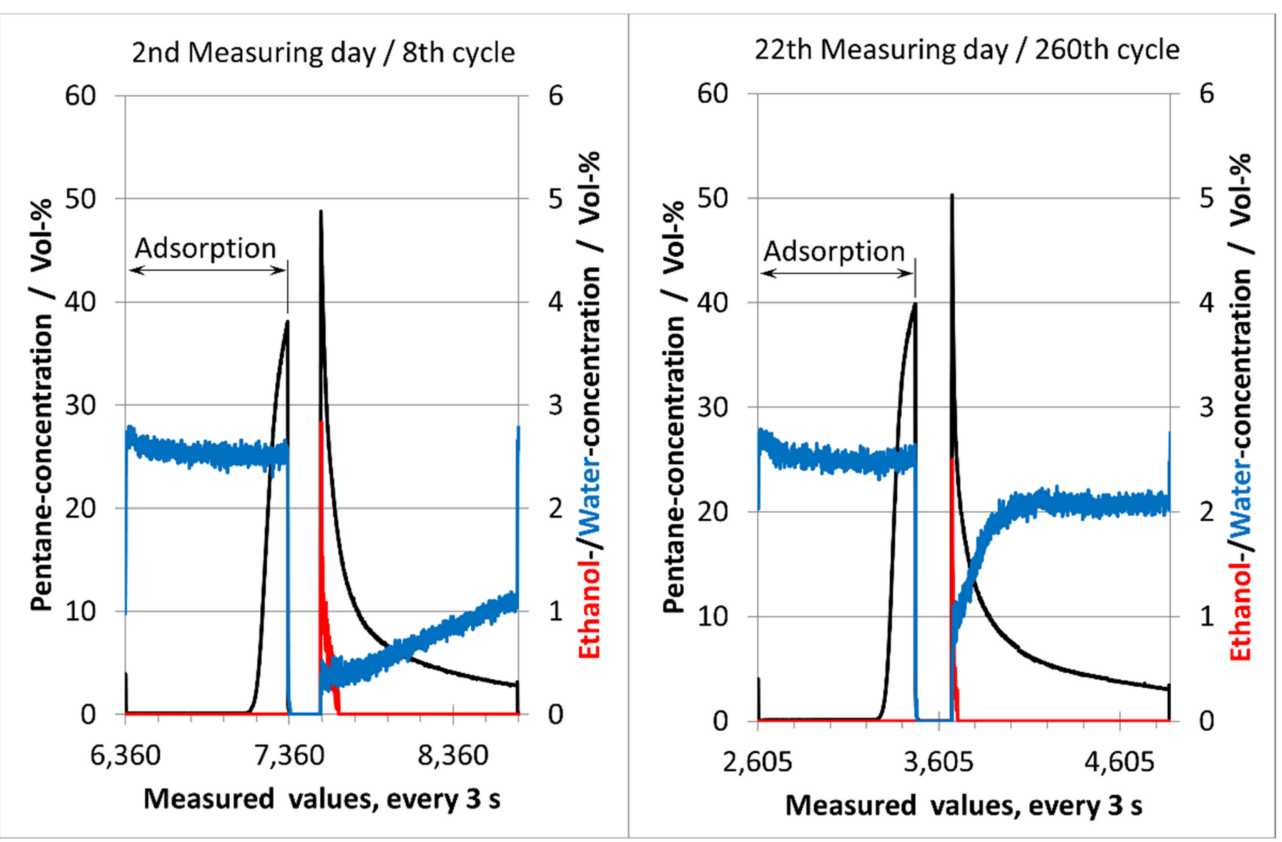

Figure 13. No breakthrough of ethanol for the system E10/humid $\mathrm{N}_{2}$ in the 8th and 260th cycle.

The investigations thus show that the regeneration of the activated carbon filter with moist nitrogen $(70 \% \mathrm{RH})$ in the case of E0 and E10 leads to an accumulation of water in the activated carbon bed. In the case of E10, however, there is also an accumulation of ethanol in the activated carbon.

\subsection{Determination of the Butane Working Capacity}

The butane working capacity (BWC) is defined as follows:

$$
m / m[\%]=\frac{m_{\text {loaded }}-m_{\text {Heel }}}{m_{\text {unloaded }}}
$$

It is defined for adsorption and desorption from dry air. If an activated carbon adsorbs butane, a certain amount of butane usually remains in the activated carbon after desorption, the so-called heel. In the tests carried out here, however, desorption was carried out with nitrogen at a relative humidity of $70 \%$, resulting in water accumulation in the activated carbon. This increases the value of $\mathrm{m}_{\text {Heel }}$ and may result in a negative value of BWC. Therefore, the butane working capacity is not a suitable instrument to test the functionality of the activated carbon filters under real conditions.

\section{Conclusions and Outlook}

The measurements have shown that a relative humidity of $70 \%$ leads to an accumulation of water in the activated carbon. If ethanol is added to the gasoline, the ethanol also accumulates in the activated carbon. Since ethanol is preferentially adsorbed over hydrocarbons, the working capacity of the filter for the gasoline vapors is reduced considerably. Thus, it was found that one reason for the increased failure of the fuel vapor retaining systems (FVRS) when using gasoline-ethanol blends is the high relative humidity of the purge air as it prevails under real conditions.

Test procedures for activated carbon filters of fuel vapor retaining systems use a relative humidity of only approximately $50 \%$ for the purge air, which is considerably lower 
than the relative humidity under real conditions. As a look at the water adsorption shows, failures of the FVRS do not occur under these unrealistic conditions.

Consequently, the butane working capacity as a test variable is also unsuitable for checking the FVRS under realistic conditions.

To ensure the functionality of the FVRS in the future, the air drawn in from the environment should be pre-dried by, for example, zeolite filters to prevent water accumulation in the activated carbon fills.

Author Contributions: Conceptualization, M.U.G., K.M., I.S., T.S., E.S.; validation, M.U.G., J.U.K., K.M., I.S., T.S. and E.S..; investigation, K.M. and M.U.G..; writing-original draft preparation, E.S. and M.U.G.; writing-review and editing, E.S., M.U.G., J.U.K. and T.S.; project administration, E.S. and T.S.; funding acquisition, E.S. and T.S. All authors have read and agreed to the published version of manuscript.

Funding: This research was funded by the Federal Ministry of Food and Agriculture (BMEL), represented by the Fachagentur Nachwachsende Rohstoffe e.V. (FNR), according to a decision of the German Federal Parliament, grant numbers 22403015 und 22403115.

Institutional Review Board Statement: Not Applicable.

Informed Consent Statement: Not Applicable.

Acknowledgments: The authors thank the members of the committee accompanying the project for their cooperation and their material support.

Conflicts of Interest: The authors declare no conflict of interest. The funders had no role in the design of the study; in the collection, analyses, or interpretation of data; in the writing of the manuscript, or in the decision to publish the results.

\section{References}

1. Directive 2009/28/EC of the European Parliament and of the Council. Available online: https://eur-lex.europa.eu/legal-content/ EN/TXT/PDF/?uri=CELEX:32009L0028 (accessed on 6 September 2021).

2. RICHTLINIE (EU) 2018/2001 DES EUROPÄISCHEN PARLAMENTS UND DES RATES vom 11. Dezember 2018 zur Förderung der Nutzung von Energie aus erneuerbaren Quellen. Available online: https:/ / data.europa.eu/eli/dir/2018/2001/oj (accessed on 6 September 2021).

3. Schmidt, H.; (TÜV Nord, Essen, Germany). Evaporative Emissions of in-use Vehicles from Germany and Sweden-Operational Conditions Affecting the Fuel System. Personal communication. 2009.

4. Schmidt, H. Annual Report 2009: Swedish In-Service Testing Programme 2008 on Emissions from Passenger Cars and Light-Duty Trucks; TÜV Nord: Göteborg, Sweden, 2009.

5. Martini, G.; Manfredi, U.; Rocha, M.; Marotta, A. Review of the European Test Procedure for Evaporative Emissions: Main Issues and Proposed Solutions; EUR 25640 EN; Publications Office of the European Union: Luxembourg, 2012. Available online: https:/ / doi.org/10.2788/72123 (accessed on 27 November 2013). [CrossRef]

6. Regelung Nr. 83 der Wirtschaftskommission der Vereinten Nationen für Europa (UN/ECE)—Einheitliche Bedingungen für die Genehmigung der Fahrzeuge Hinsichtlich der Emission von Schadstoffen aus dem Motor Entsprechend den Kraftstofferfordernissen des Motors. 2011. Available online: https:/ / op.europa.eu/de/publication-detail/-/publication/2f8f0ce5-66fb-4a38ae68-558ae1b04a5f/language-de (accessed on 22 February 2012).

7. Part 86-Control of Emissions From New and In-Use Highway Vehicles and Engines. Available online: https://www.ecfr.gov/ current/title-40/chapter-I/subchapter-C/part-86 (accessed on 8 October 2021).

8. Das Klima in Deutschland. Available online: https://www.laenderdaten.info/Europa/Deutschland/Klima.php (accessed on 18 January 2022).

9. Göbel, M.U.; Keller, J.U.; Meller, K.; Schmitz, I.; Seeger, T.; Schieferstein, E. Langzeitverhalten von Kraftstoffdampfrückhaltesystemen für Biokraftstoffe (E0, E10), Teil 1: Regeneration mit trockenem Spül-Stickstoff. Chem. Ing. Tech. 2021, 93, 1-10. [CrossRef]

10. Amendment of Regulation (EC) No 692/2008: Regulation Proposal: Determination of Evaporative Emissions From Vehicles with Positive-Ignition Engines. Annex I, L199/18; Annex VI, L199/74. Available online: https://www.legislation.gov.uk/eur/2008/6 92/body (accessed on 13 August 2018).

11. ASTM D5228: Standard Test Method for Determination of the Butane Working Capacity of Activated Carbon, 2000. Available online: https: / / www.beuth.de/de/regelwerke/astm (accessed on 29 September 2010).

12. Keller, J.U.; Seeger, T.; Schieferstein, E. Koadsorptionsgleichgewichte von Kraftstoffdämpfen an feuchten Aktivkohlefiltern. Chem. Ing. Tech. 2014, 86, 58-66. [CrossRef] 
13. Kiefer, J.; Schorsch, S.; Seeger, T.; Leipertz, A. Online-Analyse der Zusammensetzung von Brenngasen mittels RamanSpektroskopie. Chem. Ing. Tech. 2007, 79, 1327-1328. [CrossRef]

14. Kiefer, J.; Seeger, T.; Steuer, S.; Schorsch, S.; Leipertz, A. Design and Characterization of a Raman-Scattering-Based Sensor System for Temporally Resolved Gas Analysis and its Application in a Gas Turbine Power Plant. Meas. Sci. Technol. 2008, 19, 085408. [CrossRef]

15. Schlüter, S.; Krischke, F.; Popovska-Leipertz, N.; Seeger, T.; Breuer, G.; Jeleazcov, C.; Schüttler, J.; Leipertz, A. Demonstration of a signal enhanced fast Raman sensor for multi species gas analysis at a low pressure range for anesthesia monitoring. J. Raman Spectrosc. 2015, 46, 708-715. [CrossRef]

16. Eichmann, S.C.; Kiefer, J.; Benz, J.; Kempf, T.; Leipertz, A.; Seeger, T. Determination of gas composition in a biogas plant using a Raman-based sensor system. Meas. Sci. Technol. 2014, 25, 075503. [CrossRef]

17. Eichmann, S.C.; Weschta, M.; Kiefer, J.; Seeger, T.; Leipertz, A. Characterization of a fast gas analyzer based on Raman scattering for the analysis of synthesis gas. Rev. of Sci. Instrum. 2010, 81, 128104. [CrossRef] [PubMed]

18. Eichmann, S.C.; Trost, J.; Seeger, T.; Zigan, L.; Leipertz, A. Application of linear Raman spectroscopy for the determination of acetone decomposition. Opt. Exp. 2011, 19, 11052-11058. [CrossRef] [PubMed]

19. Schieferstein, E.; Seeger, T. Sensor system for long-term analysis of fuel vapour restraint systems. tm-Tech Mess. 2019, 87, 304-311. [CrossRef] 